\title{
The Effects of Illuminance and Correlated Color Temperature on Visual Comfort of Occupants' Behavior
}

\author{
Yoon, Gyu Hyon* Kim, Jeong Tai**
}

\begin{abstract}
The preferred illumination environment in accordance with the actions taken by the occupants of the rooms in residences differs significantly between different cultures and circumstances in and out of the country. In this regard, the purpose of this study is to evaluate the visual performance of various illumination environments in residential spaces by allowing the participants of the experiments to select the kind of illumination environment they prefer as the occupants of the room. For this purpose, we prepared a mock-up residential space of $6.2 \mathrm{~m} \times 4.5 \mathrm{~m} \times 2.5 \mathrm{~m}$, where the experiments for this study were conducted. Then, three illuminance settings $(30|x, 100| x$, and $150 \mathrm{~lx}$ ) and three color temperature settings (2700k, 4000k, and 6500k) were selected as the properties of the physical environment where the tests were to be conducted. The survey was conducted with 30 study subjects, with whom the level of visual comfort and the lighting adjustment evaluation by different activities were carried out. The level of visual comfort in lighting in a residential context turned to be more influenced by the color temperature and illuminance compared to other factors. Except for the test item, 'comfort,' all test items showed positive reactions when the illuminance was 150lx, which was rather light. In 'comfort,' the test subjects appeared to prefer warm color temperature of $2700 \mathrm{k}$. As we allowed the occupants to adjust the lighting environment in accordance with the conditions of the subjects and the activities they performed, the subjects regarded 150lx - 4000k setting as comfortable, while they preferred 150lx-5400k configuration for working. In case of resting, the subject answered that the configuration of $30 \mathrm{~lx}-2700 \mathrm{k}$ setting to be visually comfortable.
\end{abstract}

Keywords : Illuminance, Correlated Color Temperature, Light Emitting Diode, Mock-Up Experiment, Visual Comfort, Occupants' Behavior

\section{Introduction}

\subsection{Background and Purpose of the Study}

The lighting environment that is realized by the lighting causes various behaviors of the occupants through visual senses and recognitions. Therefore, in order to enhance the visual performance of the occupants, it is necessary to apply the lighting with sufficient consideration of the purpose of the place or the behavioral characteristics of the occupants. A residential environment is usually composed of a living room, a study, a kitchen, and a bedroom, etc. Especially, in case of the living room, it is where communication between more than 1 occupants of the residence takes place as well as other works that do not require clear visibility, in addition to many other activities.

* Main author, Department of Architectural Engineering, Kyung Hee Univ. South Korea.(khyun@khu.ac.kr)

** Corresponding author, Department of Architectural Engineering, Kyung Hee Univ. South Korea.(jtkim@khu.ac.kr)
Also, it is the characteristics of the living room environment that the behavior and pattern of the occupants of the relevant spaces varies significantly by time.

Here, a good lighting will mean providing an appropriate level of illumination for visual performance, imaging, safety, and health. In order to ensure this is the case with the lighting in the living rooms, various agencies such as IESNA, KS, and CIE provide standards to evaluate the lighting environment, with a set of certain recommendations in composing an appropriate indoors living environment. However, one cannot always expect the occupants to be satisfied with an interior environment organized in accordance with these standards. It is known that, in case of Korea, the occupants usually prefer a lighting setting of 4000 to $6000 \mathrm{k}$, while in other countries the occupants were happier with higher color temperature, ranging from 4000 to $17000 \mathrm{k}$. In case of resting behaviors, Korean occupants preferred $3000 \mathrm{k}$, while their foreign counterparts preferred something between 2700 and $4000 \mathrm{k}$. As such, it is clear that the 
preferences shown in domestic and foreign studies in color temperature differ significantly depending on environmental and cultural differences. Therefore, it is necessary to suggest a lighting environment that is relevant to Korean context.

Many of the preceding studies focused on the preferences of the occupants with given lighting environments. Therefore, it would be safe enough to say that the kind of study where the study subjects were allowed to adjust their lighting environment themselves and the resultant data of lighting preferences for visual comforts in different categories of activities are scares to be found. Therefore, in this study, we evaluate the influence of the lighting environmental elements to the level of visual comforts in different occupant behaviors and suggested a range of visual comfort in accordance with the psychology and behavior of the occupants as we allowed the test subjects to adjust the light setting of the rooms they were in.

\subsection{Scope of Study and Method}

The evaluation of the level of visual comfort and the adjustment of the lighting environment in accordance for different kinds of activities of the occupants was conducted via a survey.

Firstly, based on the existing literature and the standards introduced by IESNA and KS, the physical settings of the LED lightings that were to be used in the test were determined to establish the physical environment for the test.

Secondly, 6 evaluation items to measure the level of visual comfort felt by the study subjects were identified from the existing literature, which were, respectively, brightness, stability, naturalness, comfort, glare, and peppiness.

Thirdly, the study subjects were instructed to select and adjust the lighting environment for themselves for the activities performed by the occupants and the 4 status of the occupants (at desk, at the bookshelf, looking into a laptop monitor, and taking a break)

Fourthly, using SPSS Statistical Analysis Software, we evaluated the influence of the nine different lighting environments on the level of visual comfort. Then, we presented the range of visual comfort of the occupants in accordance with the changes in lighting environments for different activities.

\section{Physical environment of the experiment space}

\subsection{Preparation of the experiment space}

In this study, the Construction Environment Laboratory

Table 1. Physical setting of Mock-up space

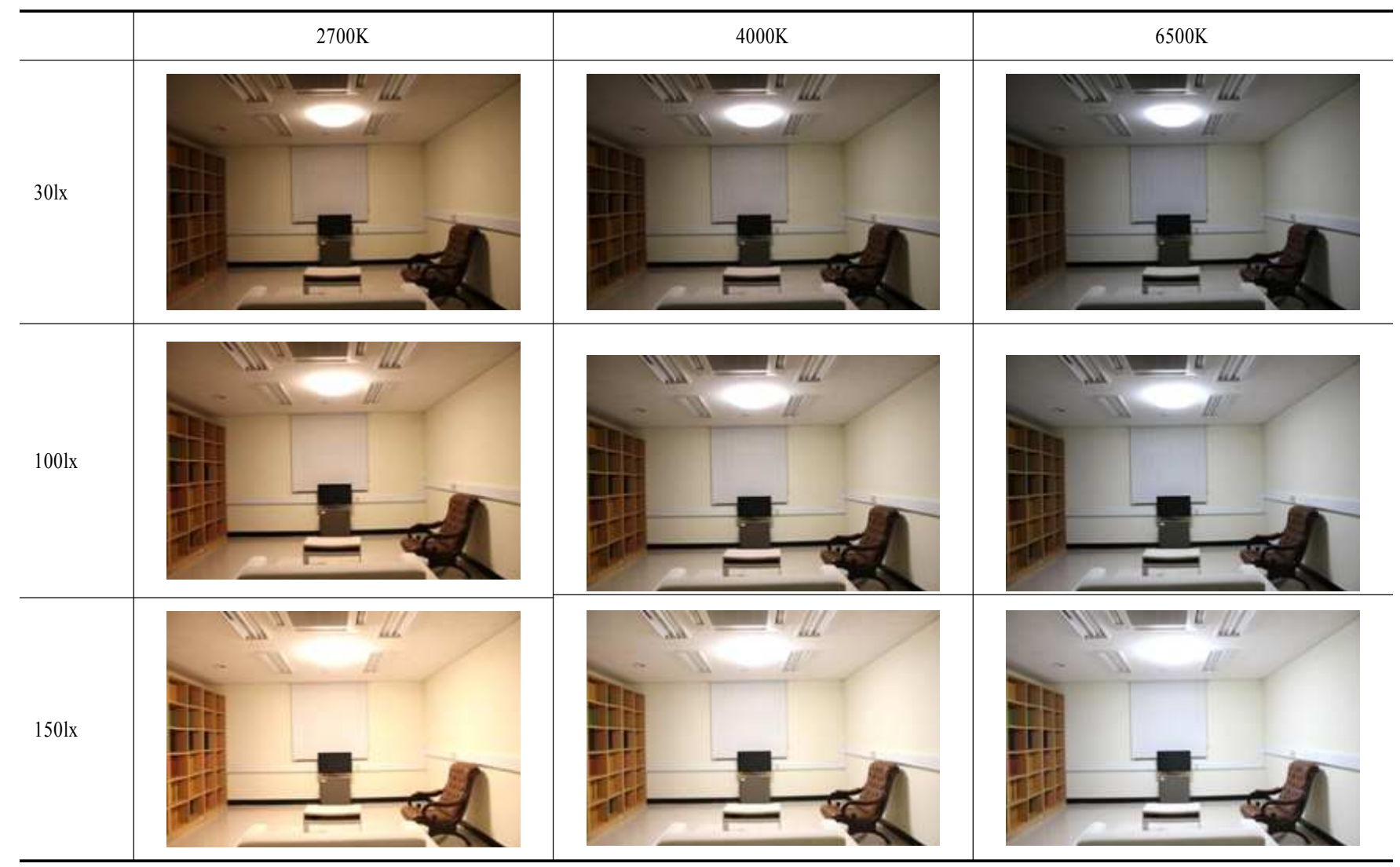


of $\mathrm{K}$ University was selected as the place of testing, and a mock - up residence environmental was build inside the laboratory. The dimension of the experiment room was $4.5(\mathrm{~W}) \times 6.2 \mathrm{~m}(\mathrm{~L}) \times 2.5(\mathrm{H})$ The windows and doors inside the experiment room were covered with the black-out curtain and the blind to prevent light from the outside entering the room. LED lights were installed as the general illumination for the room to shed the light on to the floor. Then, the occupants were place immediately below the light sources as they received participated in the survey. Also, in order to mock-up a real residential context, the place was also equipped with a carpet, a television, a table, a couch, a bookshelf, and others. In case of the bookshelf used, it was filled up with books of various colors, such as red, yellow, green, dark blue, and black, etc., so that the shapes and colors of the books may look different under different light settings. An armchair was placed on the opposite side of the bookshelf, in a way that the study subjects would face the bookshelf when they sit in it. Also, a carpet and a couch were placed on the floor, and the television was located to face the couch.

In the KS standard, the required level of illuminance for the living room as a whole range from min. 30lx to max. 601x. According to this standard, the level of illuminance for a resting environment is not supposed to go beyond 30lx, either. In addition, the IESNA standard requires that the minimum level of illuminance in a residential environment for normal social activities range from $151 \mathrm{x}$ (min.) to $601 \mathrm{x}$, while the level of illuminance for a resting context is required to be somewhere between 1001x, which is the minimum, and 4001x. In this study, since the LED lighting used was basically good for the reference illuminance for the living room, which was 30lx, and capable of providing up to 150lx at maximum, the illuminance configurations were set to 30 , 100 , and 150lx, respectively. Also, as for the color temperature, the color temperature for the warm colors was picked up below $3300 \mathrm{k}$ and that for the colder colors was picked from beyond 5000k. Therefore, the color temperature options for the lighting configurations in this study were also determined to be $2700 \mathrm{k}, 4000 \mathrm{k}$, and $6500 \mathrm{k}$. In the end, therefore, the lighting environment configurations used in this study were as presented in Table 1.

\subsection{Method}

A survey was conducted to analyze the influence of the lighting environment factors in the lighting environmental evaluation for actions by the occupants and the level of visual comfort in a residential context, in conjunction with measurement of physical properties in these aspects.

In order to analyze the physical environment resulting from the lighting environment of the experiment room, the brightness of the objects located within the sight of the occupants were measured. For this purpose, we used LMK luminance measurement device to evaluate the average luminance of the table, the couch, the bookshelves, and the laptop at $0.9 \mathrm{~m}$ high from the floor.

The survey was carried with 30 students in the Architecture Department of K University, who were in their 20s, from Oct. 1, 2013 till Nov. 11, 2013. The test space was build in the construction environment test room of K University, and in this test room, the lighting environment adjustment evaluation took place for visual comfort and the lighting environment adjustment evaluation for various activities. The survey was conducted in two different sessions per day, namely for the morning and the afternoon. A total of 15 tests were carried out for this study. In each test session, 1 occupant participated in the test. And, an individual session of the test lasted for 100 minutes. Before commencing the test, the participants were briefed on the basic personal profile and the testing process. In case of altering the lighting environment, they participants were given 3 minutes' time to adapt to the new light setting. (Fig. 1).

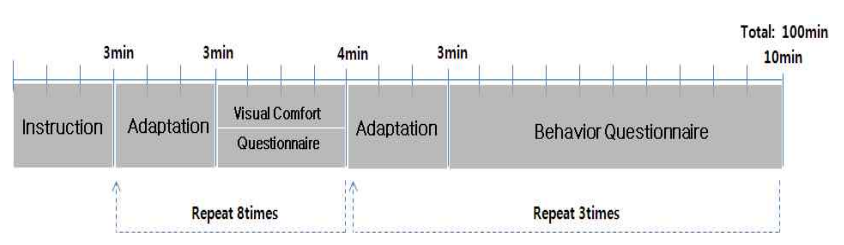

Fig 1. Test Progress

In order to assess the visual comfort, the questionnaire included 6 evaluation items, which were individually measured through Likert's 5 -points scales. The items of assessment identified for the test were, respectively, 'bright,' 'stimulating,' 'pleasant,' 'natural,' 'cheerful,' and 'comfortable.' The lighting environment adjustment evaluation for each activity was conducted as shown in $<$ Fig. 2,> where the participants (occupants) were to change the lighting environment as they wanted in accordance with the activities they were engaged in. In order to evaluate the lighting environment that was visually comfortable to the occupants, 4 activities, which were 'looking at the desk,' 'looking at the bookshelf,' 'looking at the monitor,' and 'resting,' were assessed and analyzed. 


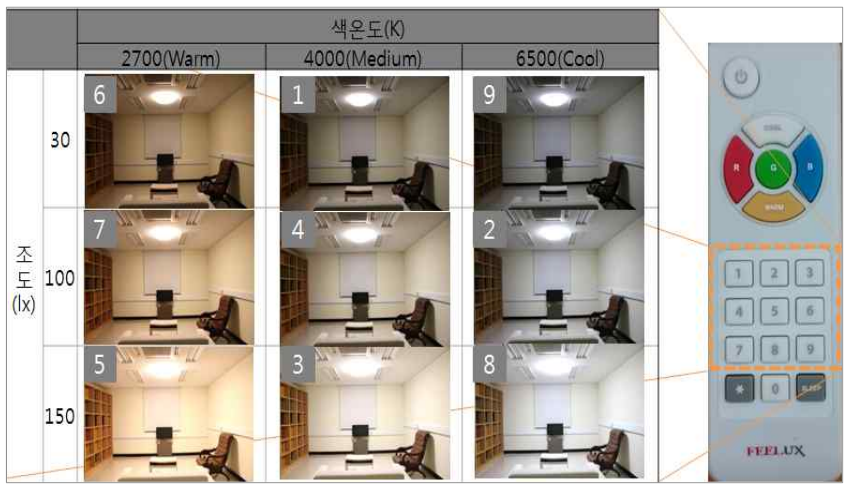

Fig 2. Lighting Control Method on Occupants' Behavior

\subsection{Analysis of the Physical Environment}

In order to analyze the physical environment of the test space and identify the range of visual comfort for each behavior (or activity, ) the luminance of the objects were measured and analyzed for each lighting environment setting. In case of the table, as shown in Table 2 , the luminance increased by 2.5 times, from $2.56 \sim 4,12 \mathrm{~cd} / \mathrm{m}^{2}$ to $8.15 \sim 8.57 \mathrm{~cd} / \mathrm{m}^{2}$, while the illuminance increased by 3 folds, from 30lx to 100lx. When it increased by 5 times, namely from $301 x$ to $1501 x$, luminance also increased by approx 5 times, from 9.55 to $11.86 \mathrm{~cd} / \mathrm{m}^{2}$, which was not significantly different from the amount of increase of illuminance. When it illuminance increased

Table 2. Luminance distribution( $a$ : sofa, $b$ : desk)

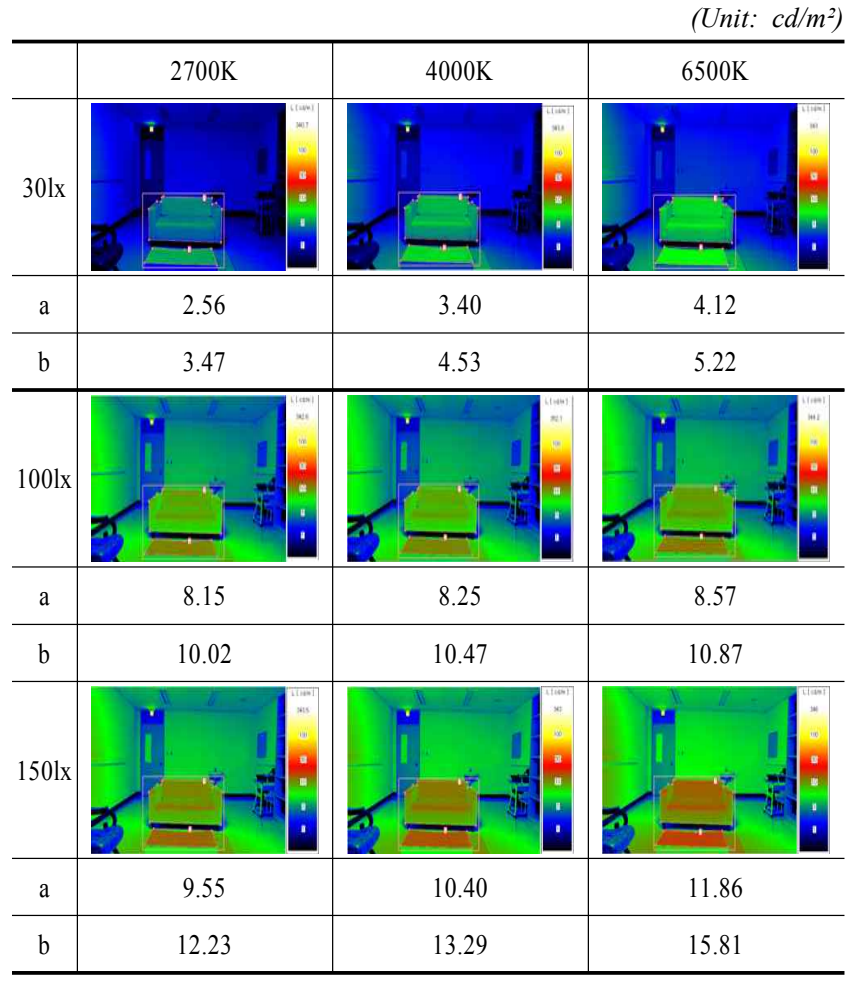

from 100lx to $1501 \mathrm{x}$, it increased from $8.15 \sim 8.57 \mathrm{~cd} / \mathrm{m}^{2}$ to $9.55 \sim 11.86 \mathrm{~cd} / \mathrm{m}^{2}$, approximately by 1.3 times. However, the increase of color temperature did not result in significant differences with luminance. The luminance of the couch was also $0.5 \mathrm{~cd} / \mathrm{m}^{2}$ in average under $301 \mathrm{x}$, $1.33 \mathrm{~cd} / \mathrm{m}^{2}$ under $1001 \mathrm{x}$ and $1.6 \mathrm{~cd} / \mathrm{m}^{2}$ under 150 , where the rate of increase for the luminance and illuminance were not significantly different for the case of the table. However, in line with the rise of the color temperature, the difference in luminance increased by approx. 30\%, which was not very big. The luminance of the bookshelf

Table 3. Luminance distribution(Bookshelves)

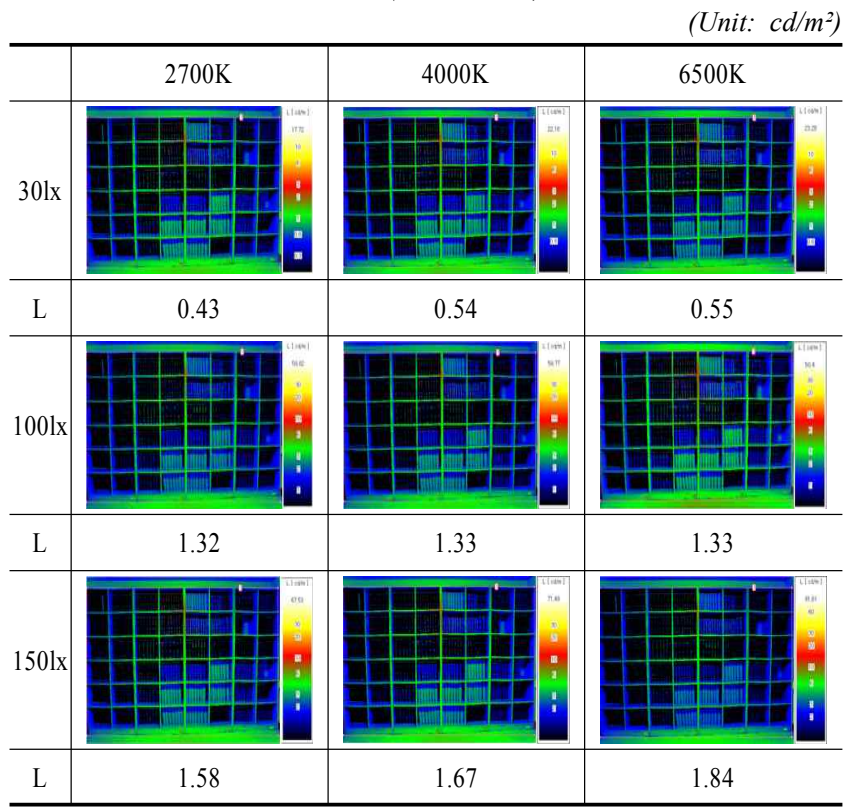

Table 4. Luminance distribution(Laptop monitor)

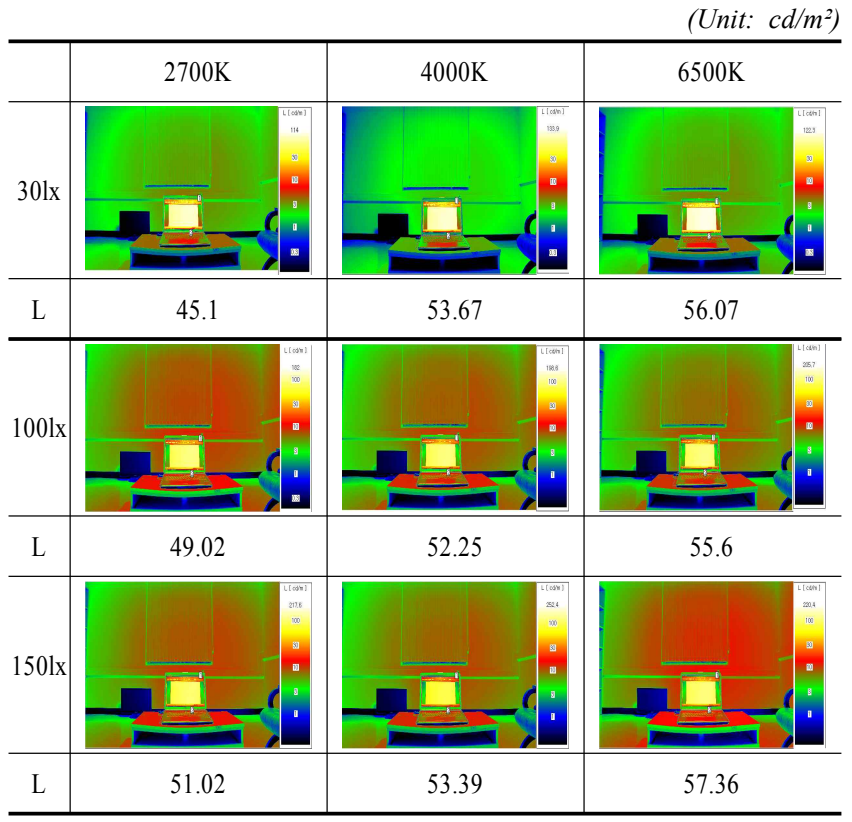


was also $0.43 \sim 0.55 \mathrm{~cd} / \mathrm{m}^{2}$ in average under $301 \mathrm{x}, 1.32 \sim$ $1.33 \mathrm{~cd} / \mathrm{m}^{2}$ under 100lx and $1.58 \sim 1.84 \mathrm{~cd} / \mathrm{m}^{2}$ under 150 , where the value of luminance was almost the same.

We believe the reason of this trend is that the bookshelf is not directly and precisely, facing the lighting instruments, the increase of the luminance and the color temperature did not affect the luminance value significantly.

We believe the reason of this trend is that the bookshelf is not directly and precisely, facing the lighting instruments, the increase of the luminance and the color temperature did not affect the luminance value significantly.

\section{Evaluation of the visual comfort of the occupants}

Depending on the lighting environment, the visual comfort of the occupants was evaluated by having them mark each of the 6 evaluation elements identified from the exiting literature. The date acquired in this process was analyzed using SPSS 18.0 software to apply descriptive statistics and ANOVA analytical methods. (Table 5).

As a result, all items except 'comfortable' showed statistically significant differences with the differences in luminance rather than those of the color temperatures. (Confidential interval

95\%). As for 'bright,' 'stimulating,' and 'pleasant,' the subjects answered positively at 1501x and 6500lx, while 'natural' and 'cheerful' were positive at $150 \mathrm{~lx}$ and 4000 lx. In case of 'comfortable,' the most positive answers were give at 30lx and 2700lx lighting environment. a)

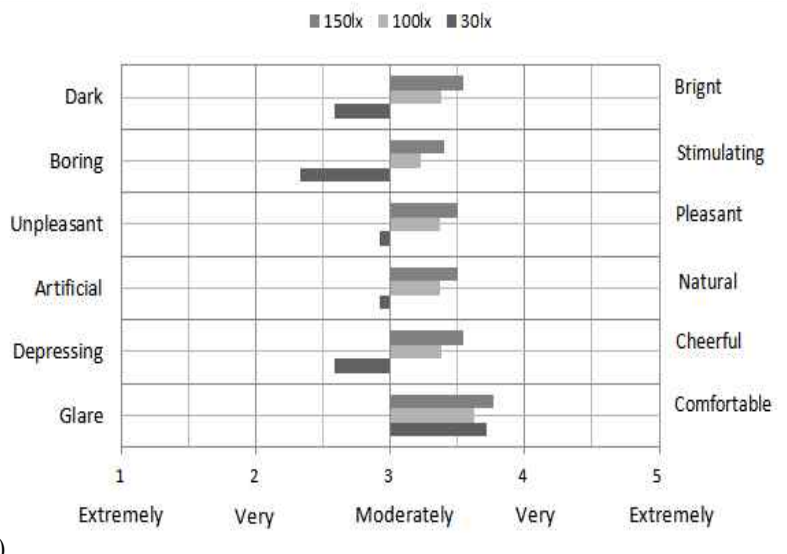

b)

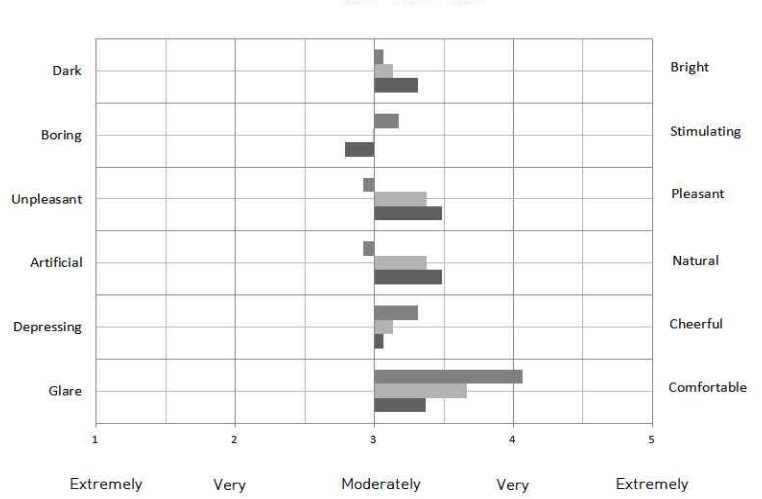

Fig 3. Visual comfort evaluation: a) Illuminance, b) Correlated Color Temperature

With the illuminance being higher, that is, when it was at 1501x, all items except for 'comfortable' had positive answers, signifying that the visual comfort is more influenced by the luminance than it is by the color temperature. (Fig. 3)

Table 5. The results of visual comfort questionnaire on different lighting environment

Average(Standard Deviation)

\begin{tabular}{|c|c|c|c|c|c|c|c|c|c|}
\hline & \multicolumn{9}{|c|}{ Lighting Environment } \\
\hline & \multicolumn{3}{|l|}{$301 x$} & \multicolumn{3}{|l|}{$1001 \mathrm{x}$} & \multicolumn{3}{|l|}{$1501 \mathrm{x}$} \\
\hline & $2700 \mathrm{~K}$ & $4000 \mathrm{~K}$ & $6500 \mathrm{~K}$ & $2700 \mathrm{~K}$ & $4000 \mathrm{~K}$ & $6500 \mathrm{~K}$ & $2700 \mathrm{~K}$ & $4000 \mathrm{~K}$ & $6500 \mathrm{~K}$ \\
\hline Brignt & $\begin{array}{l}1.77 \\
(0.63)\end{array}$ & $\begin{array}{l}2.07 \\
(0.69)\end{array}$ & $\begin{array}{l}2.07 \\
(0.87)\end{array}$ & $\begin{array}{l}3.20 \\
(0.85)\end{array}$ & $\begin{array}{l}3.60 \\
(0.81)\end{array}$ & $\begin{array}{l}3.70 \\
(1.09)\end{array}$ & $\begin{array}{l}3.47 \\
(0.73)\end{array}$ & $\begin{array}{l}3.36 \\
(1.03)\end{array}$ & $\begin{array}{l}4.20 \\
(0.76)\end{array}$ \\
\hline Stimulating & $\begin{array}{l}2.33 \\
(0.71)\end{array}$ & $\begin{array}{l}2.23 \\
(0.63) \\
\end{array}$ & $\begin{array}{l}2.43 \\
(0.94) \\
\end{array}$ & $\begin{array}{l}2.80 \\
(0.96)\end{array}$ & $\begin{array}{l}3.57 \\
(0.82)\end{array}$ & $\begin{array}{l}3.30 \\
(0.84) \\
\end{array}$ & $\begin{array}{l}3.23 \\
(0.82) \\
\end{array}$ & $\begin{array}{l}3.17 \\
(0.99)\end{array}$ & $\begin{array}{l}3.80 \\
(1.00) \\
\end{array}$ \\
\hline Pleasant & $\begin{array}{l}2.73 \\
(0.91)\end{array}$ & $\begin{array}{l}2.77 \\
(1.04)\end{array}$ & $\begin{array}{l}2.87 \\
(1.01)\end{array}$ & $\begin{array}{l}3.37 \\
(1.03)\end{array}$ & $\begin{array}{l}3.63 \\
(1.03)\end{array}$ & $\begin{array}{l}3.80 \\
(1.03)\end{array}$ & $\begin{array}{l}3.87 \\
(0.73)\end{array}$ & $\begin{array}{l}3.73 \\
(0.91)\end{array}$ & $\begin{array}{l}3.97 \\
(0.76)\end{array}$ \\
\hline Natural & $\begin{array}{l}3.13 \\
(1.04)\end{array}$ & $\begin{array}{l}2.77 \\
(0.94)\end{array}$ & $\begin{array}{l}2.87 \\
(1.07)\end{array}$ & $\begin{array}{l}3.63 \\
(1.00)\end{array}$ & $\begin{array}{l}3.53 \\
(1.04)\end{array}$ & $\begin{array}{l}2.93 \\
(1.14)\end{array}$ & $\begin{array}{l}3.70 \\
(0.95)\end{array}$ & $\begin{array}{l}3.83 \\
(0.95)\end{array}$ & $\begin{array}{l}2.97 \\
(1.07)\end{array}$ \\
\hline Cheerful & $\begin{array}{l}2.57 \\
(1.07)\end{array}$ & $\begin{array}{l}2.57 \\
(1.10) \\
\end{array}$ & $\begin{array}{l}2.63 \\
(1.03)\end{array}$ & $\begin{array}{l}3.47 \\
(1.04)\end{array}$ & $\begin{array}{l}3.50 \\
(0.86)\end{array}$ & $\begin{array}{l}3.17 \\
(1.02) \\
\end{array}$ & $\begin{array}{l}3.90 \\
(0.71)\end{array}$ & $\begin{array}{l}3.33 \\
(1.15)\end{array}$ & $\begin{array}{l}3.40 \\
(0.93)\end{array}$ \\
\hline Comfortable & $\begin{array}{l}3.93 \\
(0.78)\end{array}$ & $\begin{array}{l}3.60 \\
(0.62)\end{array}$ & $\begin{array}{l}3.60 \\
(0.77)\end{array}$ & $\begin{array}{l}4.00 \\
(0.69)\end{array}$ & $\begin{array}{l}3.50 \\
(0.94)\end{array}$ & $\begin{array}{l}3.37 \\
(1.00)\end{array}$ & $\begin{array}{l}4.27 \\
(0.69)\end{array}$ & $\begin{array}{l}3.90 \\
(0.80)\end{array}$ & $\begin{array}{l}3.13 \\
(1.11)\end{array}$ \\
\hline
\end{tabular}




\section{Lighting environment adjustment evaluation by behaviors of the occupants.}

The occupants were instructed to adjust the lighting environment of the room according to their behaviors and then asked which the most visually comfortable lighting environment was. The result showed that, as shown in Table 6 , when the occupants recognized objects such as the desk and the bookshelf, they answered that it was the most comfortable at 1501x and 40001x. That is, when the occupants recognized objects, higher luminance resulted in higher sense of comfort due to higher visibility. Also, they appeared to feel comfortable when the color temperature was not either too high or too low, such as $2700 \mathrm{k}$ and $6500 \mathrm{k}$ but was at $4000 \mathrm{k}$, which makes things white, as it is the most convenient to discern the colors. Also, when evaluating the visual comfort, the occupants thought that the most important evaluation item for visual comfort was 'comfortable,' and 'pleasant.'

In case of lighting for activities such as watching a computer monitor, most of the occupants answered that the lighting setting of $1501 \mathrm{x}$ and $6500 \mathrm{k}$ was the most desirable for working, as it in higher in both the luminance and the color temperature. Especially, it was shown that the occupants valued the elements of 'pleasant,' 'natural and'comfortable as the most important items to perceive, meaning these factors are to be considered with important when one designs lightings for a working environment.

When the occupants were taking a rest, they thought 'comfortable' element as to be the most important. In addition, the lighting setting they chose for a rest was $301 \mathrm{x}$ and $2700 \mathrm{k}$, which was low both in luminance and color temperature, which made them feel visually pleasant. However, in this case, the influence of the color

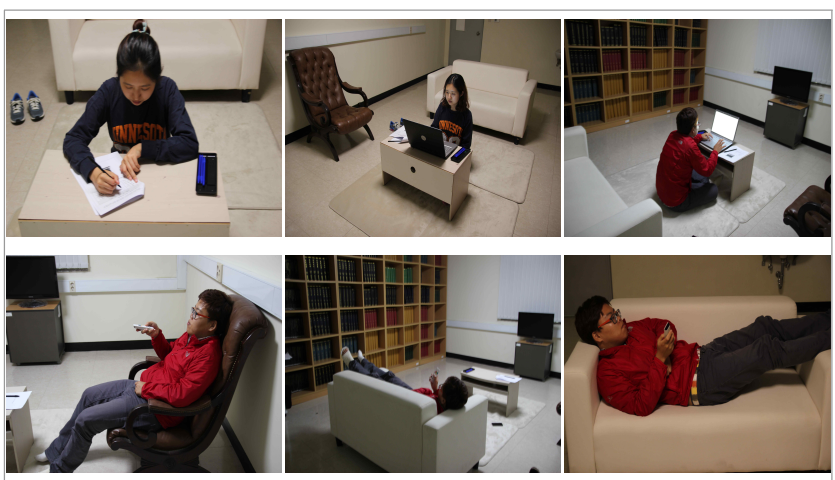

Fig 4. Lighting condition control by occupants on behavior temperature was statistically significant, rather than that from luminance, signifying that it is important to design a lighting environment by making a proper mixture of luminance and color temperature in accordance with the behavior of the occupants.

\section{Conclusion}

In this study, the visual performance and the range of visual comfort in accordance with the behavior of the occupants were measured based on the luminance and the color temperature, which were elements of the lighting environment of a residential space. The result of these measurements was as follows;

Firstly, the visual comfort under a lighting environment in a residential space was more influenced by the luminance than it was by the color temperature. The test subjects gave positive answers to all evaluation items except for 'comfortable,' when the luminance was high at 1501x. On the other hand, as for the 'comfortable' item, the subjects showed their preferences only under warm color temperature, such as $2700 \mathrm{~K}$. Therefore, in this case, the luminance mainly affected visibility [2, 4, $8]$ while the color temperature affected the atmosphere more. $[3,6,7]$

Secondly, the occupants relied that the lighting environment of $1501 \mathrm{x}-4000 \mathrm{k}$ setting was the most comfortable visually to observe objects such as a desk or a bookshelf. As for the lighting for works, they preferred $1501 \mathrm{x}-6500 \mathrm{k}$ setting, while they preferred $301 \mathrm{x}-2700 \mathrm{k}$ when they were taking a break. Such an outcome is similar to the range of visual comfort suggested in other preceding studies in Korea and other countries alike, such as, when the illuminance is set at $100 \mathrm{~lx}, 2700 \mathrm{k}$ for resting, $4000 \mathrm{k}$ for recognizing objects, and $6500 \mathrm{k}$ for working. Also, the evaluation items of the highest importance for visual comfort according to the answers from the occupants for the selected lighting environments by them were, respectively, 'pleasant' and 'comfortable.'

However, as the range of illuminance available for this study was from 301x to 150lx, it was not possible for us to provide the comfort range for higher illuminance. And, since the living rooms are used for people of various ages as they engage in various behaviors and activities, further studies would be necessary to widen the range of age of the study participants. 
The Effects of Illuminance and Correlated Color Temperature on Visual Comfort of Occupants' Behavior / Yoon, Gyu Hyon-Kim, Jeong Tai

Table 6. The frequency analysis and visual comfort evaluation on different lighting environment control by participants

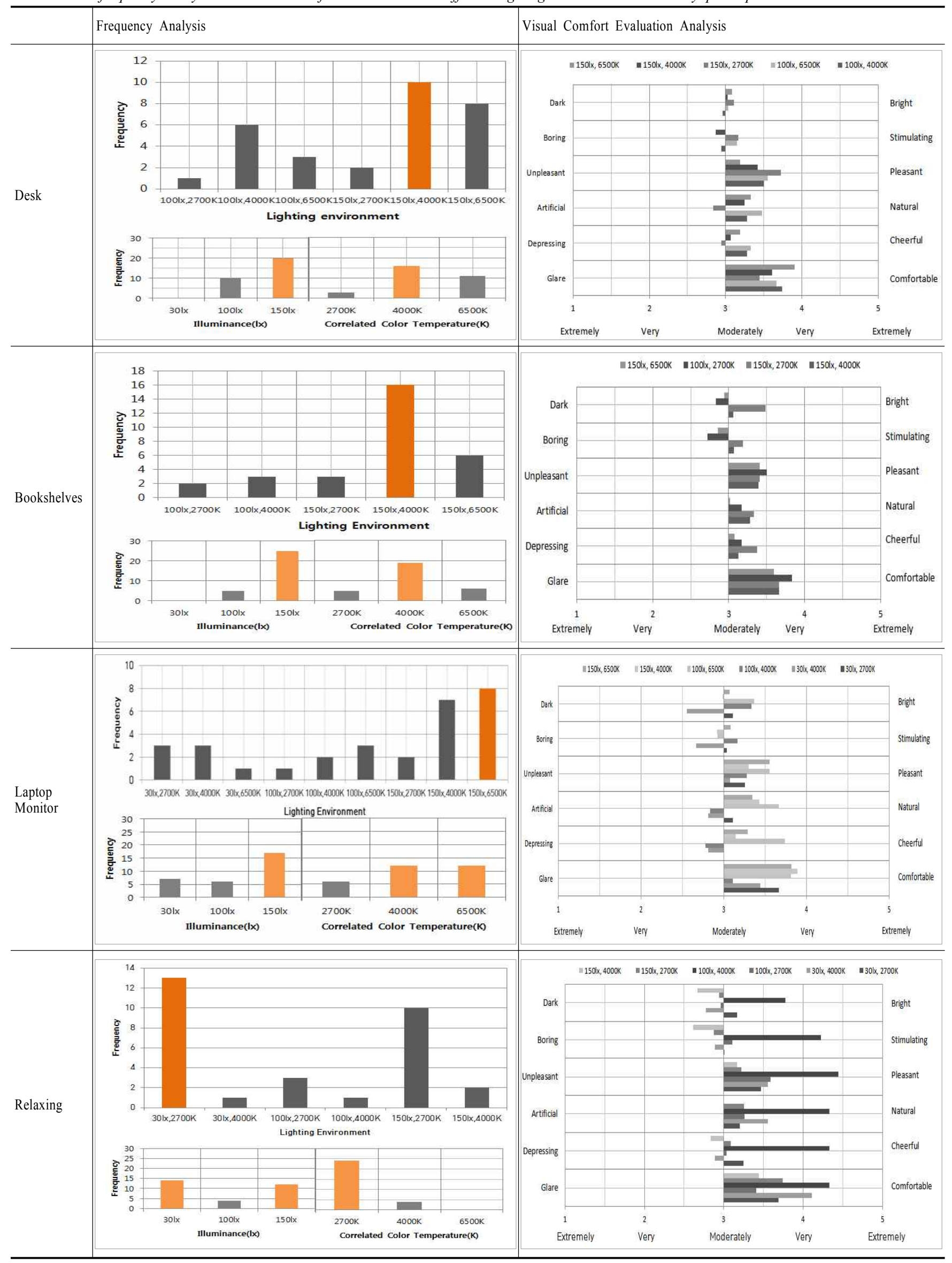




\section{Acknowledgements}

This work was supported by the National Research Foundation of Korea(NRF) grant funded by the Korea government(MSIP)(No. 2008-0061908)

\section{References}

[1] IESNA, The Lighting Handbook, 10th Edition, 2011.

[2] L.Izso, E.lang, L.Laufer, S.Suplicz and A. Horvath, Psycho Physiolog ical Performance and Subjective Correlates of Different Lighting Co nditions, Lighting Research and Techn ology, 41, 349-360, 2009.

[3] E.Rautkyla, M.Puolakka, E.Tetri and L.Halonen, Effects of Correlated Colour Temperature and Timing of Light Expo sure on Daytime Alertness in Lecture Environments, Jour nal of Light and Visual Environment, 34(2), 59-68. 2010

[4] P.R.Boyce, J.A.Veitch, G.R.Newsham, CC.Jones, J.Heerwagen, M.Myer, CM.Hunter, Occupant Use of Switching and Dimm ing Controls in Offices, Lighting Research Techonology, 38, 358-378, 2006.

[5] S.J.Wu, H.J.Kim, H.Kim, A Evaluation Lighting Environment of Rest Act in Living Room, Proceedings of The Korea Institute of Illuminating and Electrical Installation Engineers Annual Autumn Conference, 10, 3-4, 2012

[6] P.R.Mills, S.C.Tombins and L.J.Schlangen, The Effect of High Correla ted Colour Temperature Office Lighting on Employee Wellbeing and Work Performance, Journal of Circadian Rhythms, 5(2), 1-9, 2007

[7] J.H.Jang, BC Park, AS Choi, Performance Evaluation of LEDs for the Substitution of Fluorescent Lighting Sources, Proceedings of The Korea Institute of Illuminating and Electrical Installation Engineers Annual Autumn Conference, 11, 115-116, 2007

[8] J.YShin, Heathy Lighting in Buildings, Unpublished doctoral dissertation, Kyung Hee University, 2013

Received December 27 2013;

Final revision received February 10, 2014;

Accepted February 17, 2014; 